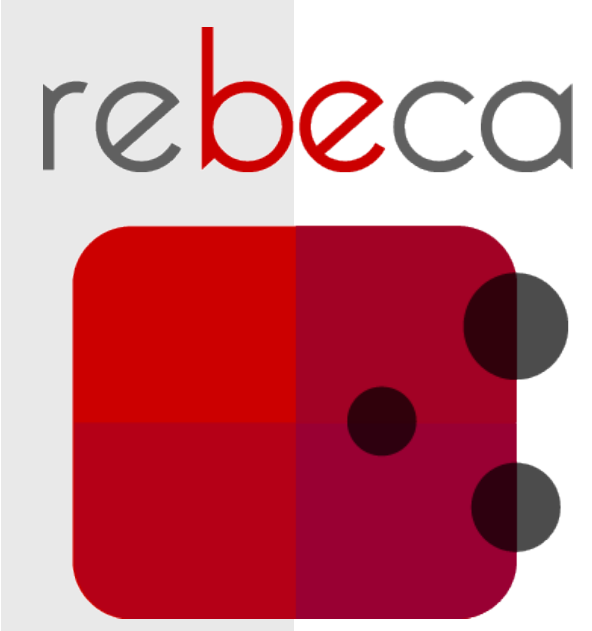

\title{
A imagem-câmera
}

Fernando Weller'

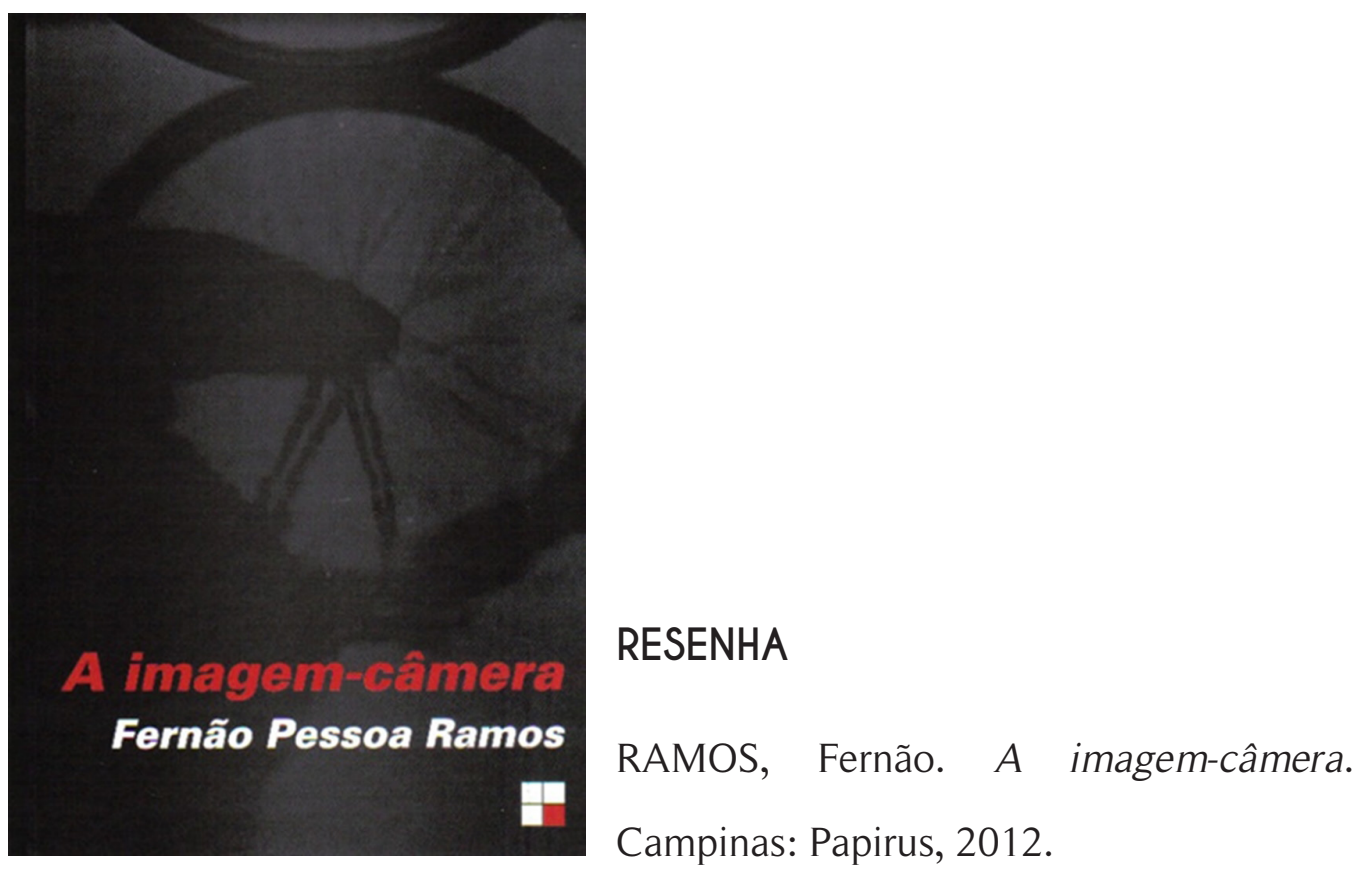

1. Doutor em Comunicação pela Universidade Federal de Pernambuco, roteirista e realizador. Email: ferwel@yahoo.com.br 
ano 1 número 2

Resenhas

A imagem-câmera, de Fernão Ramos, é um livro que se situa no campo da teoria do cinema e que, de forma ampla e ao mesmo tempo aprofundada, enfrenta as questões e impasses do pensamento em torno da imagem tecnicamente produzida, questões essas que se tornaram críticas na virada teórica em direção à semiologia e ao pós-estruturalismo dos anos 60 e 70 até os dias de hoje. $\mathrm{O}$ cerne da discussão no livro de Ramos consiste em uma reflexão sobre o vínculo essencial daquilo que o autor chama de imagem-câmera e o mundo representado, que se faz presente na imagem através da circunstância da tomada. O conceito de imagem-câmera vincula-se ao de sujeito-da-câmera. A imagem-câmera, termo que empresta o título ao livro, diz respeito a um tipo específico de imagem produzido na circunstância da tomada e com a qual ela estabelece um vínculo especular essencial garantido pelo automatismo do aparelho. O sujeito-dacâmera, que não se confunde com a figura concreta do operador da câmera, é, segundo Ramos, uma figura teórica que se vincula à posição espectatorial e existe enquanto uma potência que confere à imagem-câmera seu caráter de mediação. Afirma Ramos:

\begin{abstract}
A emoção da câmera não existe. Existe a intencionalidade do sujeito que a manipula, constituindo-se pela previsibilidade da adequação entre a forma que dá ensejo ao mecanismo de formatar da câmera e a percepção futura do espectador. O sujeito-da-câmera compõe, sempre baseado na imagem do mecanismo, a dimensão daquilo que, no momento da formação da imagem na tomada, aponta para o espectador. (RAMOS, 2012: 17)
\end{abstract}

Ao longo do livro, o autor aborda com erudição obras cinematográficas diversas, desde filmes ficcionais de diretores como Jean Renoir ou Ridley Scott, passando por exemplos no campo do documentário (Flaherty, Wiseman, irmãos Maysles) e filmes ligados ao domínio das artes plásticas (como os de Andy Wahrol), sempre tendo como horizonte teórico a crítica fenomenológica. A amplitude e a diversidade de exemplos abordados por Ramos são indícios de 
um esforço empreendido pelo autor em direção a um projeto teórico ambicioso, que reposiciona o campo dos estudos da imagem cinematográfica frente à desconfiança contemporânea na correspondência especular entre a imagem produzida e o chamado mundo real. A perspectiva de Ramos pretende restituir uma dimensão indicial, reflexa ou revelatória da imagem técnica e, para isso, o autor se volta para um conjunto de escritos vinculados à crítica cinematográfica de fundo fenomenológico em voga, particularmente no contexto francês do pós-guerra.

Ramos promove uma releitura de autores como Bazin, Laffay, Ayfre, MerleauPonty, Meunier e Mitry. Podem-se compreender duas importantes dimensões na obra de Ramos que a tornam extremamente oportuna para o campo dos estudos do cinema, sobretudo no Brasil. A primeira diz respeito a um trabalho meticuloso de releitura de textos históricos, por vezes muito referenciados em trabalhos no país e, no entanto, raramente abordados de maneira aprofundada ou remetidos ao seu contexto de debates mais amplo, tal como o faz Ramos em A imagemcâmera. Destaca-se, nesse sentido, a abordagem feita pelo autor da polêmica entre as revistas Cinéthique e Cahiers du Cinéma em meio ao contexto de maio de 68 e suas reverberações nos escritos de Baudry, Metz e Bonitzer nos anos 70, além do papel que tais debates tiveram na construção do pensamento dominante acerca do cinema nos anos que se seguiram.

É possível compreender a partir da leitura de Ramos como as teorias da desconstrução, apoiadas em um entendimento "pictórico" da imagem cinematográfica, ou seja, investidas da crítica ao ilusionismo burguês, associada à invenção da perspectiva renascentista, tornaram-se restritivas e problemáticas quando voltadas ao objeto fílmico. Se, por um lado, tal perspectiva promoveu uma revolução no cinema de formas reflexivas, metalinguísticas ou subversivas em relação ao chamado modelo clássico, por outro, ela concedeu um caráter central ao que, historicamente, pertence ao campo das exceções 
ano 1 número 2

Resenhas cinematográficas. Ramos nos lembra que, majoritariamente, as imagens cinematográficas possuem um caráter reflexo e assim são percebidas pelo espectador no momento da fruição. Assim, o autor faz uma crítica contundente ao pensamento da desconstrução voltado para o filme e retoma uma defesa do estatuto realista da imagem cinematográfica ou, em termos fenomenológicos, uma espécie de retorno às coisas mesmas, no caso, à circunstância da tomada da qual a imagem não se desvincula.

No caso específico das imagens tecnicamente produzidas pelo aparato cinematográfico, o caráter especular ou reflexo é predominante, o que não significa dizer que a imagem é, simplesmente, reflexo da realidade, mas que a imagem-câmera possui como principal potencialidade o que o autor chama de "presença primeva do que é exterior, surgindo em similitude à forma de o mundo se constelar na superfície especular" (RAMOS, 2012: 130). Tal presença originária não exclui a manipulação ou a distorção subjetiva inerente à produção de imagens, apenas o autor insiste no caráter definidor dessa relação de similitude para a imagem-câmera. Ramos assume o pensamento de fundo realista cinematográfico, fundamentalmente, à ideia baziniana de uma ontologia da imagem fotográfica definidora do caráter singular do cinema frente às outras artes. Ramos persegue decididamente uma espécie de terceira via teórica (nem a desconstrução, nem um realismo inocente) que restituiria às imagens o seu vínculo essencial com o real, ou com a "circunstância da tomada", sem, no entanto, recair no simplismo da compreensão da imagem como mera reconstrução do real, sem a mediação de um sujeito. Afirma Ramos:

Que a imagem não seja o mundo trata-se de uma evidência. Mas sua singularidade está em poder "fazer como" dentro dos traços e das figuras que a conformam como imagem-câmera. A imagem obtida pela mediação da câmera possui característica singular que a distingue na raiz de outras imagens. No entanto, é exatamente na negação da especificidade radical da imagemcâmera que boa parte da reflexão sobre ela é realizada. (RAMOS, 2012: 14) 
Uma segunda dimensão da obra de Ramos diz respeito, justamente, à preocupação em desenvolver um viés teórico original e provocador, que não se limita a repisar os textos clássicos, mas que procura conferir-lhes atualidade e, com isso, incidir no debate teórico, mesmo que tal posição tenha pouca aderência no âmbito acadêmico contemporâneo. Em seu prefácio, o autor assume o seu posicionamento "contra a corrente" da perspectiva acadêmica dominante no campo do cinema, de viés pós-estruturalista, fato que teria adiado a publicação do livro desde os seus tempos de “juventude", quando fora escrito, até o presente. Enquanto que a ênfase contemporânea nas análises acadêmicas em torno da imagem se situa na desconstrução, na dissolução ou na denúncia de um caráter essencialista da imagem e de suas implicações ideológicas, políticas ou éticas, Ramos assume corajosamente uma posição crítica às leituras dominantes, demarcando as especificidades da imagem tecnicamente produzida e retomando a rica discussão da crítica cinematográfica do contexto pré-68.

O autor tem o mérito, nem sempre comum, de perseguir uma coerência teórica que pode ser verificada em seus textos e publicações anteriores em torno da teoria do cinema e, com mais intensidade, na última década, em torno do campo do documentário. Entende-se, inclusive, após a leitura de A imagemcâmera a defesa empreendida por Ramos de uma revisão do campo documental em direção ao reconhecimento de um estatuto diferenciado de sua imagem em relação à ficção e da importância política e, sobretudo, ética que tal estatuto confere às imagens documentais. O livro de Ramos complementa, assim, a leitura de obras como Mas afinal... o que é mesmo o documentário? (2008) ou os dois volumes de sua Teoria contemporânea do cinema (2005), particularmente o seu artigo "A cicatriz da tomada: documentário, ética e imagem-intensa”, que compõe o segundo volume da obra (RAMOS, 2005: 159-226).

Trata-se, fundamentalmente, da mesma crítica que Ramos empreende contra as leituras pós-estruturalistas no cinema, que tenderiam a legitimar 
o discurso da desconstrução em exemplos de exceção, ignorando os usos e Resenhas significados das imagens no plano do cotidiano. No entanto, após a leitura de A imagem-câmera, sente-se a falta de uma abordagem mais ampla do campo para o qual Ramos direciona a sua crítica, posto que a simples caracterização de um pensamento pós-estruturalista supostamente dominante nos estudos de cinema contemporâneo é insuficiente para dar conta da diversidade e da complexidade de posições teóricas por vezes conflitantes. A desconfiança da imagem reflexa e de sua potência ilusória é tão antiga quanto a crença no vínculo essencial entre a imagem e seu referente, e não se restringe apenas aos autores vinculados ao pós-estruturalismo. Entende-se, entretanto, que o autor ocupou-se na obra em delimitar o seu campo teórico, e que tal abordagem transcenderia os objetivos do livro. 


\section{Referências bibliográficas}

RAMOS, Fernão. A imagem-câmera. Campinas, SP: Papirus, 2012.

. Mas afinal... O que é mesmo documentário? São Paulo: Ed. Senac São Paulo, 2008.

. A cicatriz da tomada: documentário, ética e imagem-intensa. In: RAMOS, Fernão (Org.). Teoria contemporânea do cinema, vol. II. Campinas, SP: Papirus, 2005. p. 159-226. 